\title{
Correction to: Variability of the GSI Index Estimated From Different Quantitative Methods
}

\author{
Gian Luca Morelli
}

Published online: 30 October 2017

(C) Springer International Publishing AG 2017

\section{Correction to: Geotech Geol Eng (2015) 33:983-995 \\ DOI 10.1007/s10706-015-9880-x}

The year of publication for Dr. Sari's book chapter 'Incorporating variability and/or uncertainty of rock mass properties into GSI and RMi systems using Monte Carlo method' is 2014 and not 2015, as erroneously indicated in the reference list of the original publication of this article. The correct reference is:

Sari M (2014) Incorporating variability and/or uncertainty of rock mass properties into GSI and RMi systems using Monte Carlo method. Eng Geol Soc Territ 6:843-849

\section{G. L. Morelli $(\bowtie)$}

Geotecna Progetti S.r.1, Milan, Italy

e-mail: gl.morelli.geo@gmail.com;

gianluca.morelli@geotecna.it 